\title{
Simultaneous percutaneous nephrolithotomy and early endoscopic ureteric realignment for iatrogenic ureteropelvic junction avulsion during ureteroscopy
}

\author{
Marawan El Tayeb, MD; Matthew J. Mellon, MD; James E. Lingeman, MD \\ Indiana University School of Medicine, Department of Urology, Indianapolis, IN
}

Cite as: Can Urol Assoc J 2015;9(11-12):E882-5 http://dx.doi.org/10.5489/cuaj.2830

Published online December 14, 2015.

\section{Abstract}

We present a case report of successful management of ureteropelvice junction avulsion during ureteroscopy successfully managed with simultaneous percutaneous nephrolithotomy and early endoscopic ureteral realignment.

\section{Introduction}

The incidence of ureteral injury and overall complications during ureteroscopy ranges from 0 to $28 \% .^{1-5}$ latrogenic ureteral injury varies from minor mucosal petechiae to erosion, perforation, and rarely complete ureteral avulsion. ${ }^{6}$ Factors associated with higher complication rates during ureteroscopy are longer surgery times, treatment of renal calculi, surgeon inexperience, and previous irradiation. ${ }^{1,3,7}$ Ureteral stents are the cornerstone in the management of ureteral injury. If stent placement is not possible following ureteral injury, placement of a percutaneous nephrostomy tube is required for renal drainage until elective repair can be accomplished..$^{1,8-10}$ Several authors have reported reasonable rates of success with ureteroscopic ureteral realignment for iatrogenic ureteral injury during gynecologic and general surgical procedures..$^{9-13}$ However, to our knowledge, there has not been a previous report of successful endoscopic ureteral realignment following avulsion of the ureter at the level of the ureteropelvic junction.

\section{Case report}

A 59-year-old female with a long history of nephrolithiasis had a 7-mm right renal pelvic calculus. Ureteroscopic treatment was performed at an outside institution. There was some difficulty with ureteral dilatation and UPJ avulsion of the ureter was suspected associated with insertion of the ureteral access sheath. A safety guide wire was not used during the procedure. Subsequently, a guide wire was not able to be passed beyond the injury into the renal collecting system and, therefore, a stent could not be placed. A $5 \mathrm{~F}$ ureteral catheter was placed through the avulsed proximal ureter projecting into the retroperitoneum. The patient was transferred to Indiana University Health Methodist Hospital for subsequent management.

The patient has a history of cirrhosis, splenomegaly, and thrombocytopenia with a platelet count of 52,000 and an INR of 1.5. Ureteroscopy was performed confirming complete avulsion of the ureter (Fig. 1). A stent could not be placed and a ureteral catheter was replaced into the retroperitoneum near the kidney. The following day a percutaneous nephrostomy was inserted by Interventional Radiology (Fig. 2). The patient was then returned to the operating room and placed in a prone split-leg position to allow for simultaneous antegrade and retrograde access to the ureter. The percutaneous access was dilated to 30F and an Amplatz sheath was positioned into the kidney (Fig. 3). Nephroscopy identified the stone in the renal pelvis which was removed. The UPJ was identified and noted to be very small in caliber. A flexible ureteroscope was passed antegradely through the UPJ confirming that the avulsion occurred at this level. A sensor guide wire (Boston Scientific, Natick, MA) was passed through the ureteral catheter which had been previously placed but, unfortunately, could not be identified with the flexible ureteroscope. The UPJ was dilated with a $6 \mathrm{~mm}$ Uromax balloon (Boston Scientific Corp., Natick, MA) so that a larger instrument could be used to identify the guide wire (Fig. 4). The sensor guide wire was exchanged for a glide wire which provided for more coiling of the wire in the retroperitoneum. Using the flexible nephroscope, the glide wire was immediately located and pulled through and through. The glide wire was exchanged for an Amplatz super stiff wire. An 8F, 24cm JJ stent was then placed in antegrade fashion. A 16F Foley catheter was placed in the bladder and a 10F Cope loop was placed in the kidney. 


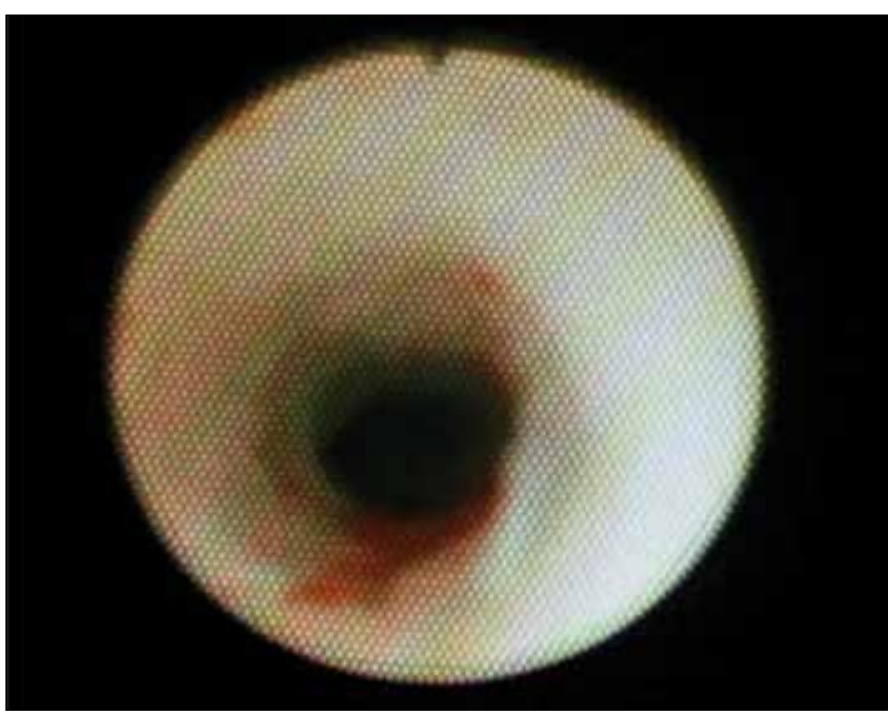

Fig. 1. Avulsed ureteropelvic junction.

An antegrade nephrostogram was done two weeks following stent placement. No extravasation was evident so the nephrostomy tube was removed (Fig. 5). Eight weeks postoperatively, the ureteral stent was removed and a retrograde pyelogram was performed showing no extravasation, apparent healing of the UPJ, and mild hydronephrosis (Fig. 6). A CT urogram done two weeks following stent removal showed continuity of the UPJ and ureter with mild hydronephrosis and no extravasation. An IVP done 10 weeks later showed resolution of hydronephrosis with no extravasation (Fig. 7). The patient remained asymptomatic. An MRI was done one year following the endoscopic realignment as part of an evaluation of the patient's cirrhosis, which revealed no hydronephrosis and a normal appearing kidney.

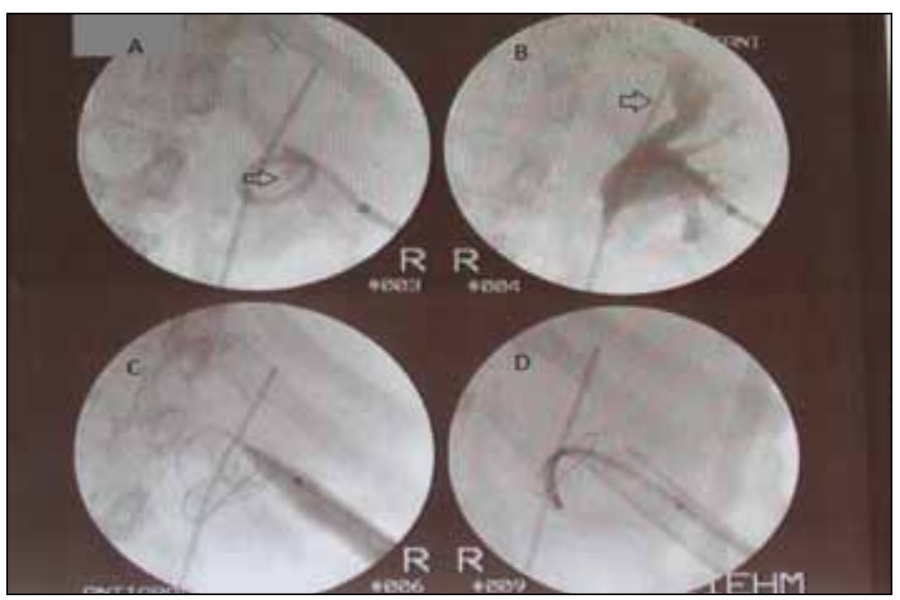

Fig. 3. A: 9-mm stone in the renal pelvis; B: ureteral catheter in the retroperitoneum outside the renal pelvis; $C$ : hydrophilic wire coiled in the retroperitoneum; D: flexible ureteroscope inserted antegradely.

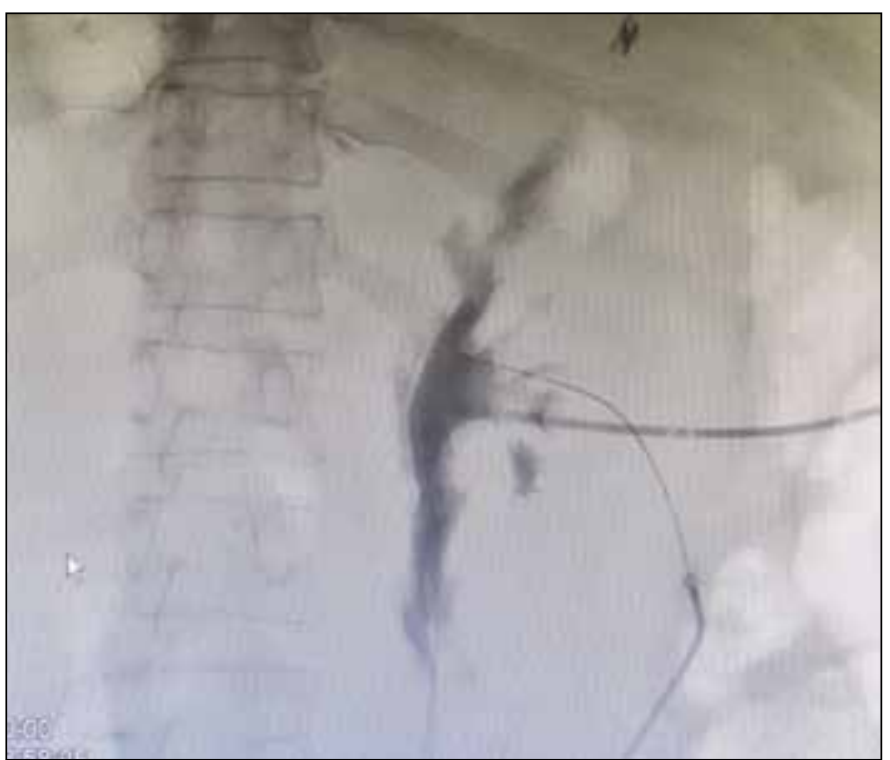

Fig. 2. Extravasation of contrast with complete disruption of the UPJ.

\section{Discussion}

The incidence of ureteral perforation during ureteroscopy ranges from $1 \%$ to $15.4 \%$, while the feared complication of ureteral avulsion is rare in contemporary reports. ${ }^{3-5,7,9,14,15}$ Complication rates during ureteroscopy correlate with prolonged operative duration, as well as surgeon experience. ${ }^{3}$ The treatment of impacted ureteral calculi are also associated with a greater rate of complications, as well as unsuccessful interventions. ${ }^{16}$ In this case, use of a ureteral access sheath was thought to be associated with avulsion of the ureter from the UPJ. Interestingly, Traxer and colleagues reported that ureteral injury is common with ureteral access sheath placement, although they reported no avulsions in the series. They also noted that pre-ureteroscopic stenting decreased the incidence of higher grades of ureteral trauma. ${ }^{6}$

Endourologic management of complete avulsion of the UPJ has not been previously reported to our knowledge. Early diagnosis and treatment are important and, in this case, realignment was performed within 48 hours of the injury. The referring urologist was suspicious of avulsion leading to prompt referral of the patient. A satisfactory outcome in this case was likely enhanced by the minimal displacement of the proximal ureter (about $2-3 \mathrm{~cm}$ ).

For these complex procedures, patients should be placed in the prone split-leg position allowing simultaneous antegrade and retrograde access to the avulsed ureter. Following removal of the offending stone, coiling of a hydrophilic wire in the retroperitoneum either antegradely or retrogradely increases the chances of visualization of the wire from either side and subsequent pull through of the wire.

In our case, nephrostomy drainage was maintained for two weeks and ureteral stenting for a total of eight weeks. 


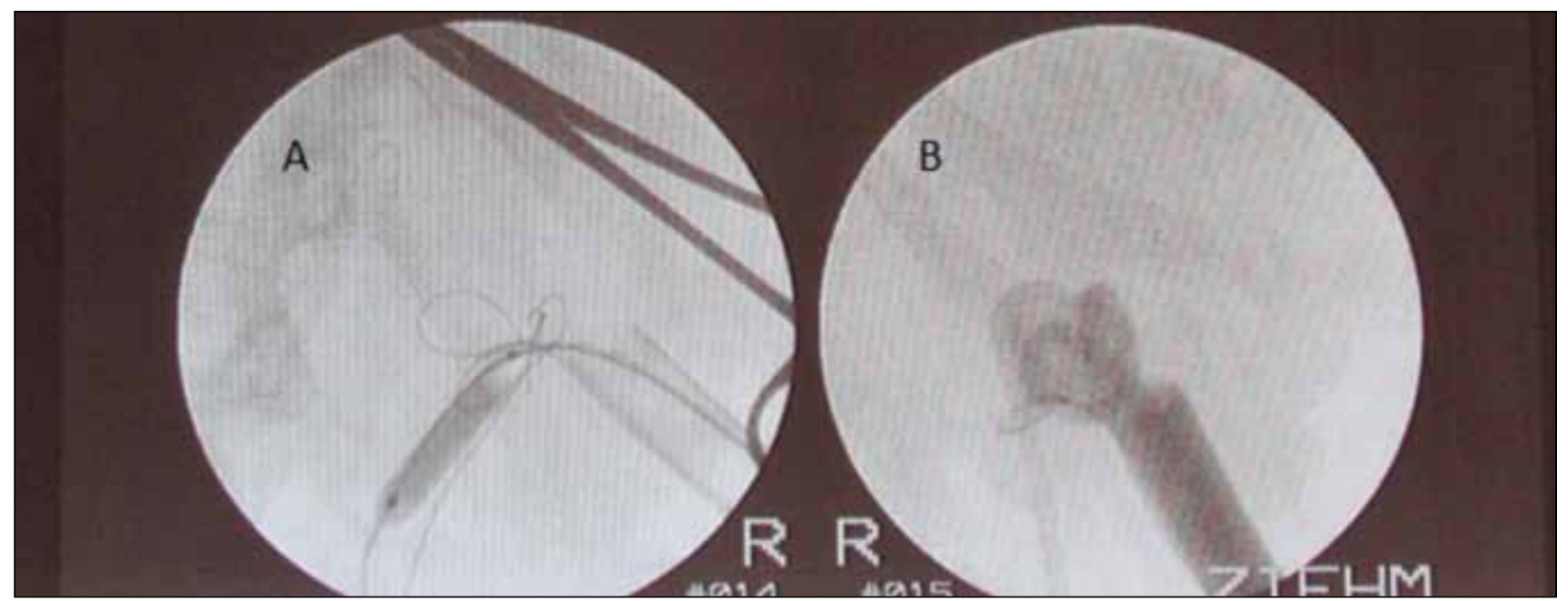

Fig. 4. A: Uromax ballon dilating the tight avulsed UPJ. B: JJ stent and Cope loop nephrostomy tube in place.

Although some patients may develop secondary ureteral strictures, the approach presented herein should not prevent subsequent open or laparoscopic surgical repair if ultimately required.

\section{Conclusion}

Early endoscopic ureteric realignment is a safe and feasible method to manage iatrogenic ureteric avulsion obviating the need for open surgical repair.

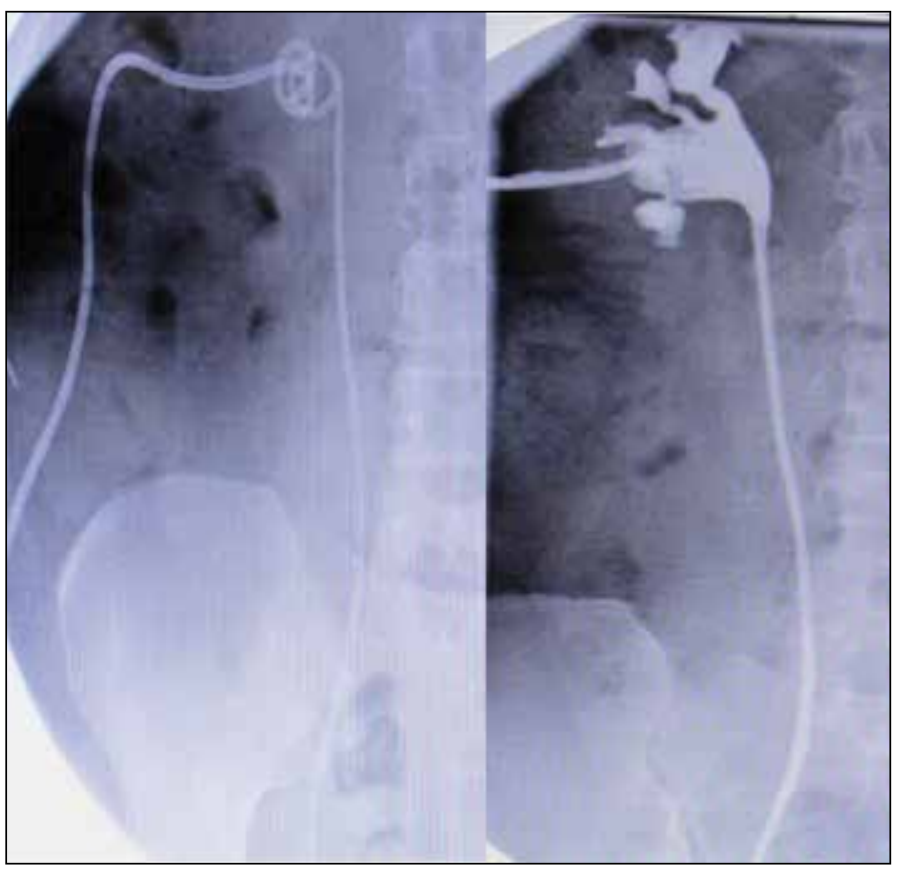

Fig. 5. Antegrade nephrostogram showing intact UPJ with no extravasation.
Competing interests: Dr. El Tayeb and Dr. Mellon declare no competing financial or personal interests. Dr. Lingeman is or has been an Advisory Board member for and has received honoraria from from Boston Scientific.

This paper has been peer-reviewed.

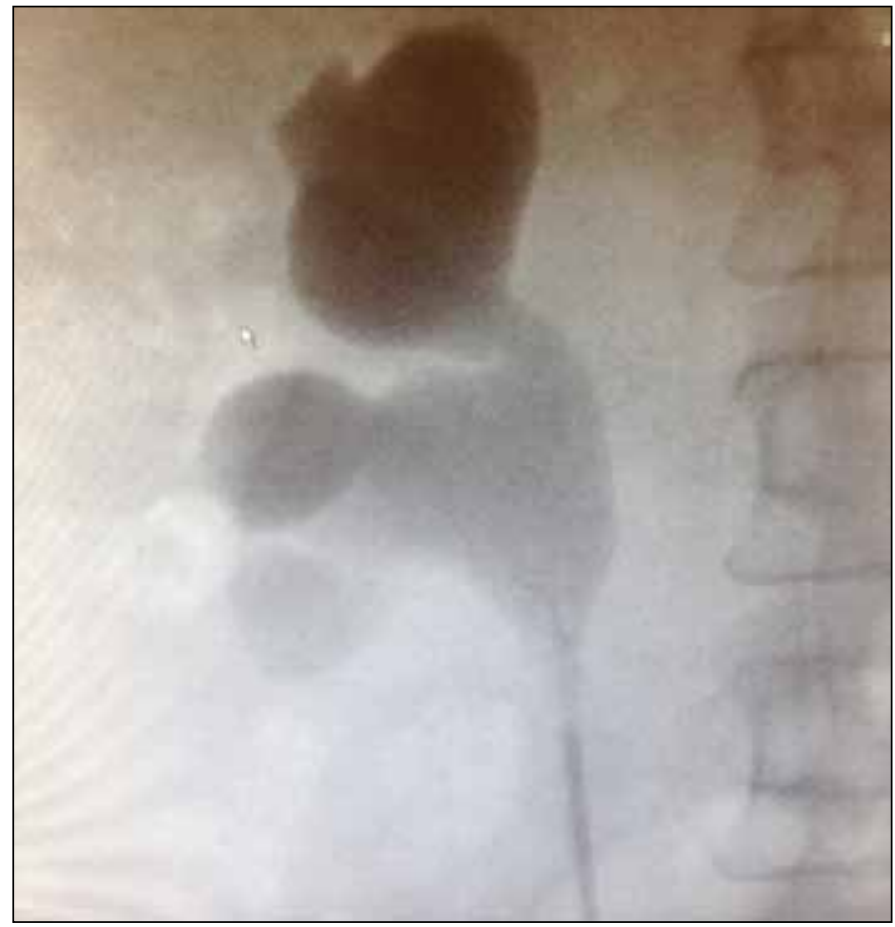

Fig. 6. Retrograde pyelogram at time of ureteral stent removal showing intact UPJ. 


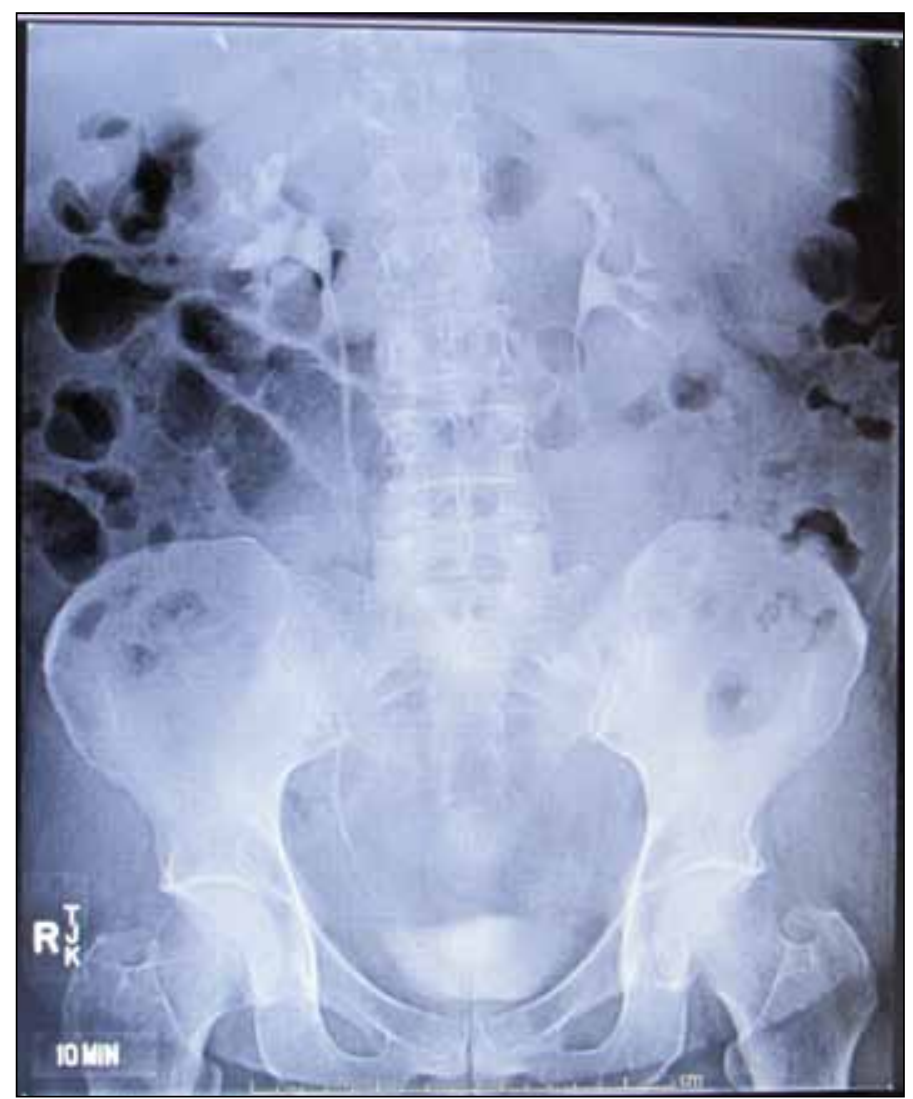

Fig. 7. 18 weeks postoperative IVP.

\section{References}

1. Huffman JL. Ureteroscopic injuries to the upper urinary tract. Urol Clin North Am 1989;16:249-54.

2. Johnson DB, Pearle MS. Complications of ureteroscopy. Urol Clin North Am 2004;31:157-71. http:// dx.doi.org/10.1016/S0094-0143(03)00089-2

3. Schuster TG, Hollenbeck BK, Farber GJ, et al. Complications of ureteroscopy: Analysis of predictive factors. J Urol 2001;166:538-40. http://dx.doi.org/10.1016/S0022-5347(05)65978-2

4. De la Rosette J, Denstedt J, Geavlete P, et al. The clinical research office of the endourological society ureteroscopy global study: Indications, complications, and outcomes in 11,885 patients. J Endourol 2014;28:131-9. http://dx.doi.org/10.1089/end.2013.0436

5. Mandal S, Goel A, Singh MK, et al. Clavien classification of semirigid ureteroscopy complications: A prospective study. Urology 2012;80:995-1001. http://dx.doi.org/10.1016/i.urology.2012.05.047

6. Traxer 0 , Thomas $A$. Prospective evaluation and classification of ureteral wall injuries resulting from insertion of a ureteral access sheath during retrograde intrarenal surgery. J Urol 2013;189:580-4. http://dx.doi. org/10.1016/i.juro.2012.08.197

7. Geavlete $P, G$ Georgescu $D$, Niţă $G$, et al. Complications of 2735 retrograde semirigid ureteroscopy procedures: A single-center experience. J Endourol 2006;20:179-85. http://dx.doi.org/10.1089/ end.2006.20.179

8. Flam TA, Malone MJ, Roth RA. Complications of ureteroscopy. Urol Clin North Am 1988;15:167-81.

9. Schoenthaler M, Wilhelm K, Kuehhas FE, et al. Postureteroscopic lesion scale: A new management modified ogan injury scale—Evaluation in 435 ureteroscopic patients. J Endourol 2012;26:1425-30. http:// dx.doi.org/10.1089/end.2012.0227

10. Pastore AL, Palleschi $G$, Leto $A$, et al. Endoscopic rendezvous procedure for ureteral iatrogenic detachment: Report of a case series with long-term outcomes. J Endourol 2015;29:415-20. http://dx.doi. org/10.1089/end.2014.0474. Epub 2014 Nov 18.

11. Koukouras D, Petsas $T$, Liatsikos $E$, et al. Percutaneous minimally invasive management of iatrogenic ureteral injuries. J Endourol 2010;24:1921-7. http://dx.doi.org/10.1089/end.2010.0153

12. Ku JH, Kim ME, Jeon YS, et al. Minimally invasive management of ureteral injuries recognized late after obstetric and gynaecologic surgery. Injury 2003;34:480-3. http://dx.doi.org/10.1016/S00201383(02)00412-6

13. Abboudi H, Ahmed K, Royle J, et al. Ureteric injury: A challenging condition to diagnose and manage. Nat Rev Urol 2013;10:108-15. http://dx.doi.org/10.1038/nrurol.2012.254

14. Geavlete $P$, Georgescu $D$, Nita $G$, et al. Complications of 2735 retrograde semirigid ureteroscopy procedures: A single center experience. J Endourol 2006;20:179-85. http://dx.doi.org/10.1089/ end.2006.20.179

15. Stoller ML, Wolf JS, Hofmann R, et al. Ureteroscopy without routine balloon dilation: An outcome assessment. J Urol 1992;147:1238-42.

16. Degirmenci T, Gunlusoy B, Kozacioglu Z, et al. Outcomes of ureteroscopy for the management of impacted ureteral calculi with different localizations. Urology 2012;80:811-5. http://dx.doi.org/10.1016/i. urology.2012.05.007

Correspondence : Dr. James E. Lingeman, Indiana University School of Medicine, 1801 Senate Blvd., Suite 220, Indianapolis, IN 46202; lingeman@iuhealth.org 